\title{
The clinical significance of hyperfiltration in diabetes
}

\author{
G. Jerums • E. Premaratne $\cdot$ S. Panagiotopoulos • \\ R. J. MacIsaac
}

Received: 20 November 2009 / Accepted: 9 April 2010/Published online: 23 May 2010

(C) Springer-Verlag 2010

\begin{abstract}
Glomerular filtration rate is commonly elevated in early diabetes and patients with this symptom are arbitrarily considered to have hyperfiltration. The prevalence of hyperfiltration in type 1 diabetes varies from less than $25 \%$ to more than $75 \%$. The corresponding figures in type 2 diabetes are significantly lower, ranging between $0 \%$ and more than $40 \%$. Several factors, methodological and biological, may contribute to the wide variation in estimates of hyperfiltration prevalence. Methodological differences in measurement and evaluation of GFR apply in particular to the handling of plasma disappearance curves of filtration markers. Biological factors that may influence GFR in the hyperfiltration range include glycaemic control, diabetes duration, BMI, sex, pubertal status in type 1 diabetes and age in type 2 diabetes. Hyperglycaemia may influence GFR and albuminuria, and may therefore confound the evaluation of hyperfiltration as an independent risk factor for diabetic nephropathy. Adequate assessment of the relationship between glycaemic control, GFR and AER therefore requires serial measurements of all three variables followed by multivariate analysis. A recent meta-analysis of ten type 1 diabetes studies concluded that the presence of hyperfiltration at baseline more than doubled the risk of developing micro- or macroalbuminuria at follow-up. However, not all studies allowed for confounding factors or regression dilution bias. Future studies will therefore need to address the independent role of hyperfiltration, not only in the evolution of albuminuria, but also in the subsequent decline of GFR.
\end{abstract}

G. Jerums $(\bowtie) \cdot$ E. Premaratne $\cdot$ S. Panagiotopoulos $\cdot$

R. J. MacIsaac

Endocrine Centre, Austin Health,

Heidelberg Repatriation Hospital,

Level 2, Centaur Building, 300 Waterdale Road, PO Box 5444,

Heidelberg West, Victoria 3081, Australia

e-mail: ah-endo@unimelb.edu.au
Keywords Ageing · Albuminuria $\cdot$ Animal models $\cdot$ Clinical studies - Diabetic nephropathy - GFR decline - Glycaemic control $\cdot$ Hyperfiltration $\cdot$ Nephromegaly $\cdot$ Review

\section{Abbreviation \\ RAS Renin-angiotensin system}

\section{Introduction}

Early type 1 diabetes is associated with increases in kidney size and GFR. This state of 'hyperfiltration' reflects hyperglycaemia and can be reversed with intensive insulin therapy [1]. Although patients with newly diagnosed type 1 diabetes may have increased AER at presentation, hyperfiltration usually precedes changes in albuminuria by several years [2]. However, it remains uncertain whether hyperfiltration is merely a marker of glycaemic control or whether it exerts a pathogenetic role in human diabetic nephropathy, independently of factors such as $\mathrm{HbA}_{1 \mathrm{c}}$, blood pressure, age and pubertal status, duration of diabetes, AER and smoking [3, 4]. Experimental models of hyperfiltration include hyperfiltration at the single-nephron level, in the whole kidney in the intact animal and in the remnant kidney after subtotal nephrectomy $[5,6]$. The latter has a human counterpart in advanced kidney disease. However, it is not clear whether hyperfiltration at the single-nephron or remnant-kidney level is an accurate replica of hyperfiltration in patients with early type 1 diabetes. The present review addresses the evidence that hyperfiltration is an independent predictor and possible pathogenetic factor for diabetic nephropathy. It does this with special emphasis on longitudinal studies of progression of AER and rates of decline of GFR. In particular, it examines the evidence 
linking hyperfiltration to the onset of microalbuminuria and seeks to rationalise apparently divergent results obtained in several studies $[7,8]$. Initial hyperfiltration has also been associated with an increased rate of decline of GFR in some studies, and the onset and duration of this decline are also reviewed $[9,10]$.

A systematic search for articles linking 'hyperfiltration' and 'diabetes' was performed using Medline. Publications linking hyperfiltration to onset of microalbuminuria and/or to subsequent decline of GFR in type 1 or type 2 diabetes were included in the review.

\section{Measurement of GFR}

In defining hyperfiltration, GFR can be treated as a continuous or dichotomous variable. However, hyperfiltration has been traditionally defined as GFR $>2$ standard deviations above the mean GFR in control participants. The threshold for hyperfiltration has ranged from 125 to $140 \mathrm{ml} \mathrm{min}^{-1} 1.73 \mathrm{~m}^{-2}$ in various studies $[9,11,12]$.

The traditional and most accurate method for direct measurement of GFR is the constant infusion technique using a marker such as insulin. This relies on achieving a stable plasma level of a marker that is cleared from the circulation only by the kidney. In addition, renal handling of the marker must be by glomerular filtration without any contribution by tubular reabsorption or secretion. The procedure takes several hours and requires serial measurements of plasma levels as well as timed urine samples. Although this is the gold standard it is not suited for largescale studies.

In the majority of studies of hyperfiltration, GFR has been measured with filtration markers such as iohexol or isotopically labelled markers such as iothalamate, ethylene diamine tetracetic acid and dithiopentaacetic acid, using a single injection technique. Alternative methods for assessing hyperfiltration include measurement of endogenous filtration markers such as cystatin $\mathrm{C}$ or creatinine. However, creatinine-based methods tend to underestimate GFR in the hyperfiltration range.

The variables determining the prevalence of hyperfiltration are both methodological and biological. Methodological factors are particularly important in interpreting the results of plasma clearance methods for measurement of GFR using a single injection technique. A regression equation devised by Brochner-Mortensen corrects for the assumptions of a one compartment model and allows accurate determination of GFR when a single injection technique is used [13]. Without this correction, GFR calculated from the final slope of the plasma disappearance curve overestimates true GFR, especially in the normal and hyperfiltration ranges [14]. Methodological factors may also influence interpretation of serial measurements of GFR. When resolution of hyperfiltration is based on results of only two measurements, it may be difficult to differentiate between regression to the mean and a true biological change.

\section{Prevalence of hyperfiltration in type 1 diabetes}

In type 1 diabetes, the reported prevalence of hyperfiltration usually ranges from $40 \%$ to $60 \%[2,9,15]$. However, the prevalence of hyperfiltration in other studies in type 1 diabetes has varied from as low as $13 \%$ [16] to as high as $67 \%$ [17]. Apart from hyperglycaemia, other factors influencing the prevalence of hyperfiltration in type 1 diabetes include the level of albuminuria, duration of diabetes, younger age of disease onset and pubertal status [11].

\section{Effect of glycaemic control on hyperfiltration in type 1 diabetes}

In type 1 diabetes, the most important determinant of hyperfiltration is uncontrolled hyperglycaemia. However, not all studies have shown that hyperfiltration is related to glycaemic control. Early hyperfiltration, occurring before insulin treatment or in the first months of type 1 diabetes, can be reversed by insulin therapy [18]. By contrast, late or persistent hyperfiltration may persist for years and may not be associated with glycaemic control when assessed by $\mathrm{HbA}_{1 \mathrm{c}}$ measurements several years after the onset of diabetes. This may be related to a biphasic relationship between plasma glucose and GFR. One study in patients with type 1 diabetes has demonstrated a positive correlation between glucose and GFR at glucose levels below $13.5 \mathrm{mmol} / \mathrm{l}$, but at higher glucose levels GFR tended to be lower [19]. The same investigators subsequently showed that when glucose levels were clamped at $12.5 \mathrm{mmol} / \mathrm{l}$ for $80 \mathrm{~min}$, GFR rose by $12 \%$ in hyperfiltering type 1 diabetic patients, with no change in GFR in normofiltering diabetic or in normal control participants [20].

There is clear evidence that prolonged intensive insulin therapy, even after 12 years of diabetes, can normalise hyperfiltration [1]. In a prospective study of 12 patients with type 1 diabetes, hyperfiltration and mean $\mathrm{HbA}_{1}$ over $10 \%$, six were randomised to insulin pump therapy and six to conventional therapy for 12 months. Insulin pump therapy reduced $\mathrm{HbA}_{1}$ levels to around $7 \%$ (equivalent to $\mathrm{HbA}_{1 \mathrm{c}} \sim 5.5 \%$ ) after 3 months. Mean GFR decreased from 150 to under $130 \mathrm{ml} \mathrm{min}^{-1} 1.73 \mathrm{~m}^{-2}$ and was maintained at this level over 12 months, whereas GFR was unchanged in the control group. At 1 month after cessation of insulin 
pump therapy, GFR rebounded into the hyperfiltration range [1]. This indicates that glycaemic control remains an active modulator of GFR several years after onset of diabetes.

\section{Hyperfiltration in type 2 diabetes}

Estimates of the prevalence of hyperfiltration in type 2 diabetes have varied from $0 \%[21,22], 6 \%$ [23] and $35 \%$ to $45 \%$ in recently diagnosed patients $[12,24,25]$. A prevalence of $62 \%$ was reported by Vedel [26]. The most likely factors responsible for the marked variability of these estimates are age, glycaemic control, duration of diabetes and the method used for expressing GFR in obese patients.

In the non-diabetic population, there is an age-related annual decrease in GFR of $1 \mathrm{ml} \mathrm{min}-1.73 \mathrm{~m}^{-2}$ after the age of 40 years [27]. In older patients with type 2 diabetes, hyperfiltration can be masked by this age-related decline in GFR. We documented the prevalence of hyperfiltration with and without adjustment for age in patients with type 2 diabetes in a clinic-based cross-sectional study of 662 patients with type 2 diabetes [28]. The overall prevalence of hyperfiltration was $7.4 \%$ without age correction and $16.6 \%$ after adjustment for age (Fig. 1).

The influence of ageing and variable duration of disease on GFR is minimised in Pima Indians who have obesity and early onset of type 2 diabetes with well documented disease duration. Studies in normoalbuminuric Pima Indians with mean BMI exceeding $30 \mathrm{~kg} / \mathrm{m}^{2}$ have shown that when GFR is indexed to surface area, hyperfiltration is not more prevalent than in non-diabetic participants [29]. However, if GFR is expressed as $\mathrm{ml} / \mathrm{min}$, then GFR exceeds levels in non-diabetic Pima Indians matched for

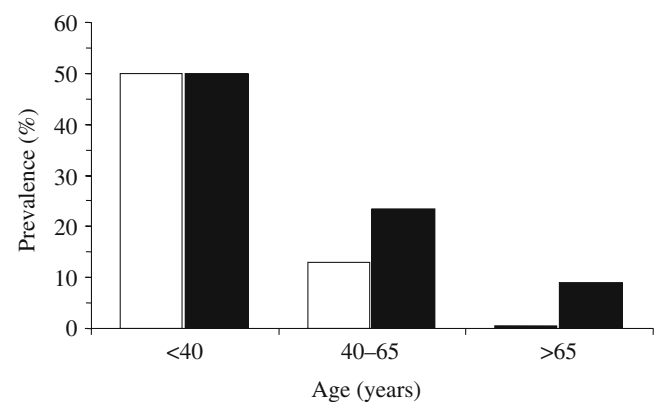

Fig. 1 The prevalence of hyperfiltration in 662 patients with type 2 diabetes after stratification by definitions that were unadjusted for age (white bars) and age-adjusted (black bars). The age-unadjusted threshold for hyperfiltration was defined arbitrarily as a BrochnerMortensen corrected GFR of $>130 \mathrm{ml} \mathrm{min}^{-1} 1.73 \mathrm{~m}^{-2}$. To account for the age-related decline in GFR, hyperfiltration was defined as GFR $>130 \mathrm{ml} \mathrm{min}^{-1} 1.73 \mathrm{~m}^{-2}$ minus $1 \mathrm{ml} \mathrm{min}^{-1} 1.73 \mathrm{~m}^{-2}$ per year after the age of 40 [28]. Patients with hyperfiltration: $<40$ years 11/22 (both stratifications); 40-65 years 37/288 (unadjusted), 67/288 (adjusted); >65 years 1/354 (unadjusted), 32/354 (adjusted)
BMI [30]. Serial measurements in 194 Pima Indians enabled assessment of GFR and AER trajectories during 4 years of follow-up [30]. The study showed that type 2 diabetes is characterised by hyperfiltration in patients with newly diagnosed as well as in those with long-standing diabetes, except in the presence of macroalbuminuria. However, baseline GFR predicted neither increasing AER nor declining GFR during follow-up.

Three other studies have examined the potential role of hyperfiltration in the evolution of GFR and AER in type 2 diabetes. The first reported that higher systolic blood pressure at baseline was related to a faster rate of decline of GFR [31].

A second study examined GFR in 32 normoalbuminuric patients over 5 years [25]. In the 13 patients with hyperfiltration at entry, GFR declined annually by $7.3 \mathrm{ml} / \mathrm{min}$, approximately three times faster than in normofiltering patients or in age-, sex- and BMI-matched normal individuals. In multiple regression analysis, higher baseline GFR and age, but not $\mathrm{HbA}_{1 \mathrm{c}}$ or blood pressure, were related to a faster rate of decline of GFR. A third study reported serial measurements of isotopic GFR in 11 hyperfiltration patients [12]. After a follow-up of 3 to 16 years, seven of these patients still showed hyperfiltration and GFR remained above $100 \mathrm{ml} \mathrm{min}^{-1} 1.73 \mathrm{~m}^{-2}$ in all individuals.

In summary, longer follow-up will be needed in future studies to determine whether initial hyperfiltration and faster decline of GFR represent an initial phase of a process leading to subnormal GFR levels corrected for age.

\section{Hyperfiltration independent of diabetes}

Obesity as such has been associated with hyperfiltration [32]. It has also been claimed that the metabolic syndrome is associated with hyperfiltration, as estimated by the Cockcroft-Gault formula [33]. However, GFR estimates by the Cockcroft-Gault formula may be spuriously elevated in obese participants. A recent study, using methods which do not systematically overestimate GFR in obese participants, found that elevated GFR was not associated with the metabolic syndrome and did not predict onset of diabetes [34].

In a study of 12 non-diabetic participants with severe obesity (BMI $>38 \mathrm{~kg} / \mathrm{m}^{2}$ ) and nine non-obese participants, GFR measured by inulin clearance was $136 \pm 8$ and $90 \pm 5$ $\mathrm{ml} / \mathrm{min}$, respectively $(p<0.0005)$ [35]. In another study by the same group, GFR determined by inulin clearance in eight participants with severe obesity decreased from $145 \pm 14$ to $110 \pm 7 \mathrm{ml} / \mathrm{min} 12$ months after gastroplasty, with a concomitant $32 \%$ decrease in BMI [36]. However, in both of the above studies, GFR was not corrected for body surface area. 
Studies in hypertensive non-diabetic participants, using creatinine clearance as an index of GFR, have suggested that elevated GFR may be an indicator of early target organ damage $[37,38]$. In the PREVEND (Prevention of Renal and Vascular Disease) study, a community based study in 7,728 non-diabetic participants, GFR estimated by creatinine clearance was proportional to BMI [39] and elevated AER was independently associated with hyperfiltration assessed by creatinine clearance [40]. However, assessment of hyperfiltration by the Cockcroft-Gault formula or by creatinine clearance is less reliable than direct measurement of GFR. It is therefore not clear whether these results in non-diabetic participants can be equated with hyperfiltration in diabetes.

\section{Mechanisms of hyperfiltration in diabetes}

Based mainly on experiments in rodent models, glomerular and tubular theories have been advanced for the development of hyperfiltration in diabetes (Fig. 2). In the 1980s, Zatz showed that haemodynamic rather than metabolic factors mediate diabetic glomerulopathy in the streptozotocin diabetic Munich-Wistar rat [41]. Hyperfiltration was also shown to mediate glomerular injury in the setting of ageing, renal ablation and intrinsic renal disease [42]. By contrast, others have suggested that hyperfiltration is secondary to increased proximal tubular resorption of glucose and sodium in animal models of diabetes [43] and have shown that blockade of renal tubular growth prevents development of hyperfiltration [44].

Studies in patients with type 1 diabetes support the concept that primary increases in proximal tubular sodium resorption lead to glomerular hyperfiltration through decreased tubulo-glomerular feedback at the macula densa [45]. However, diabetes-induced hyperfiltration has been shown to occur in adenosine A1-receptor-deficient mice,

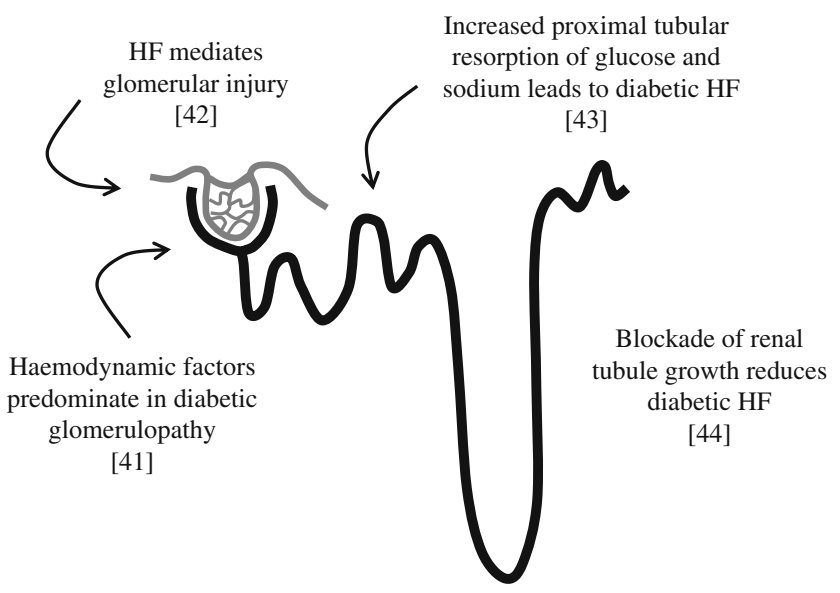

Fig. 2 Glomerular and tubular theories for the development of hyperfiltration (HF) in diabetes which lack the tubulo-glomerular feedback mechanism [46]. Further studies are therefore needed to determine whether explanations proposed for the aetiology of hyperfiltration in animal models can be applied to the development of hyperfiltration in human diabetes.

\section{Hyperfiltration and nephromegaly}

Hyperfiltration and renal enlargement are both associated with early diabetes and distinguishing one from the other is difficult. Early studies in young adults with type 1 diabetes and elevated GFR showed that kidney weight, corrected for body surface area, was increased by $22 \%$ after a mean duration of diabetes of 4.9 years [47]. However, GFR per gram of kidney weight was the same in diabetic and control participants.

It has been suggested that hyperfiltration is a pathogenetic factor for nephromegaly in humans [48], but in animal models of diabetes renal enlargement precedes hyperfiltration [49]. A cross-sectional study of 177 adolescents with type 1 diabetes showed that renal enlargement is associated with microalbuminuria as well as with pubertal duration [50]. Participants with kidney volume $>300 \mathrm{ml} / 1.73 \mathrm{~m}^{2}$ were eight times more likely to have microalbuminuria than those with kidney volume $<300 \mathrm{ml} / 1.73 \mathrm{~m}^{2}$.

In a longitudinal study of 146 normoalbuminuric patients with mean duration of type 1 diabetes of 9.5 years, increased kidney volume at baseline, but not hyperfiltration, was a predictor of progression to microalbuminuria in 27 patients [10]. Patients predisposed to microalbuminuria showed a stable increase in kidney volume along with a faster initial decline in GFR. However, mean attained GFR remained within the normal range over 4 years, indicating that resolution of hyperfiltration could not be separated from onset of a progressive decline in GFR to subnormal levels. Also, the possibility that hyperfiltration prior to the study was related to the development of microalbuminuria could not be excluded. Further work is therefore needed to establish a pathogenetic role for hyperfiltration and/or nephromegaly in diabetic nephropathy.

\section{Hyperfiltration at whole-kidney and single-nephron level}

Hyperfiltration is arbitrarily defined as being present when whole-kidney GFR exceeds 125 to $140 \mathrm{ml} \mathrm{min}^{-1} 1.73 \mathrm{~m}^{-2}$ in an individual with two functioning kidneys $[9,11,12]$. In early diabetes, hyperfiltration at the whole-kidney level may reflect a generalised increase in single-nephron GFR, but a contribution by increased nephron endowment cannot be ruled out. Soon after the onset of diabetic nephropathy, 
early decreases in whole-kidney GFR may reflect a generalised decrease in single-nephron GFR. By contrast, at later stages of nephropathy, nephron dropout leads to compensatory hyperfiltration in remaining nephrons [5].

In animal models of renal damage, including diabetic nephropathy, a decrease in dietary protein intake retards the progression of renal disease [41] while decreasing hyperfiltration at the single-nephron level [6]. Similarly, in patients with type 1 diabetes and GFR $<60 \mathrm{ml} \mathrm{min}^{-1}$ $1.73 \mathrm{~m}^{-2}$, a reduction of dietary protein intake from 1.0 1.1 to $0.6-0.7 \mathrm{~g} / \mathrm{kg}$ daily has been shown to slow the annual rate of decline of GFR from between 6 and $10 \mathrm{~min}^{-1} 1.73 \mathrm{~m}^{-2}$ to $<2 \mathrm{ml} \mathrm{min}^{-1} 1.73 \mathrm{~m}^{-2}$ [51, 52]. This is consistent with the concept that hyperfiltration at the singlenephron level may contribute to GFR decline at the wholekidney level in advanced kidney disease. However, a link between hyperfiltration at the whole-kidney level and subsequent progressive GFR decline to subnormal levels has not yet been established in human diabetes.

\section{Nephron endowment as a determinant of hyperfiltration}

Studies in animal models have suggested that increased single-nephron GFR, as seen with nephron loss, and increased glomerular capillary hydraulic pressure, as seen in diabetes [53], both contribute to progressive loss of renal function. However, Brenner's group has proposed that a single pathogenic factor may be insufficient to initiate progressive loss of renal function in humans. Instead, it has been suggested that multiple initiating and perpetuating factors lead to progressive loss of nephrons, as part of a 'multi-HIT' hypothesis [54]. Initiating factors include diabetes, decreased nephron number, high normal urinary albumin excretion, raised blood pressure, greater age, obesity, non-Caucasian ethnicity and a family history of renal disease. Decreased nephron number, proteinuria and raised blood pressure may also act as progression promoters, thereby perpetuating renal disease, along with obesity, anaemia, smoking, high dietary protein intake and AfricanAmerican race [55]. A possible explanation for varying results in human studies of the relationship of hyperfiltration to changes in AER and GFR is that diabetes-related increases in GFR are superimposed on varying GFR levels prior to the onset of diabetes, which may in turn be related to nephron endowment at birth [56]. It follows that GFR, when estimated accurately before the onset of diabetes, may make it possible to distinguish between the contributions of nephron endowment and diabetes-related increments in GFR to the GFR attained after onset of diabetes.

The relationship between nephron number and early renal structural changes has been studied in type 1 diabetic patients with a single, transplanted kidney and in patients with two mature kidneys matched for diabetes duration [57]. Glomerular structural variables were similar in both groups despite an approximately twofold disparity in nephron number. This suggests that reduced nephron number as such is not associated with accelerated development of diabetic nephropathy. However, it does not exclude the possibility that reduced nephron number may play a role in progression of advanced diabetic nephropathy.

\section{Relationship between hyperfiltration and renal ultrastructural changes}

Three prospective studies have investigated the possibility that hyperfiltration predicts renal ultrastructural changes in type 1 diabetes patients. In a study performed in 15 adolescents with $>5$ years' duration of type 1 diabetes, marginally increased AER (15-30 $\mu \mathrm{g} / \mathrm{min})$ and a mean GFR of $137 \mathrm{ml} \mathrm{min}^{-1} 1.73 \mathrm{~m}^{-2}$ at up to 5 years before biopsy, analysis of glomerular ultrastructure showed that some components were increased compared with a healthy control group [58]. On multivariate analysis, more than $70 \%$ of the variation in basement membrane thickness and in the overall glomerulopathy index was predicted by 5 year mean $\mathrm{HbA}_{1 \mathrm{c}}$, diabetes duration and GFR measured 2 to 5 years before biopsy. It was concluded that previous hyperfiltration may add to the prediction of glomerular morphological changes. Another study was performed in 36 predominantly normoalbuminuric patients with type 1 diabetes, who were aged 13 to 25 years and had disease duration of 7 to 19 years [59]. During the first 10 years of diabetes, GFR was significantly higher than that of control participants, with median GFR peaking at $150 \mathrm{ml} \mathrm{min}$ $1.73 \mathrm{~m}^{-2}$ at 2 years after diagnosis. Multiple regression analysis showed that the most important association with an increase in glomerular basement membrane thickness was mean pre-biopsy $\mathrm{HbA}_{1 \mathrm{c}}$. However, there was no significant correlation between mean pre-biopsy GFR and renal structural variables.

The International Diabetic Nephropathy Study was performed in 243 children and adults aged 10 to 40 years with diabetes duration of 2 to 10 years and GFR $142 \pm$ $28 \mathrm{ml} \mathrm{min}^{-1} 1.73 \mathrm{~m}^{-2}$ [60]. The study found that baseline renal ultrastructural changes, including glomerular basement membrane width and fractional volume of mesangium and mesangial matrix, were related to diastolic blood pressure but not to hyperfiltration [60]. However, higher GFR and increased glomerular basement membrane width at baseline did predict the later development of microalbuminuria after 5 years of follow-up [61].

In summary, glycaemic control and hyperfiltration have been associated with renal ultrastructural changes in 
diabetes, but it is not clear if hyperfiltration as such plays a pathogenetic role.

\section{Resolution of hyperfiltration in clinical trials}

Several observational studies have been performed to assess the long-term evolution of GFR in patients with hyperfiltration and type 1 diabetes (Fig. 3). Five studies prospectively categorised participants according to baseline hyperfiltration or normofiltration and followed the cohort for 3 to 18 years (Fig. 3). In these studies, there was a greater decline in GFR in the groups with initial hyperfiltration. However, final GFR remained at or above $100 \mathrm{ml} \mathrm{min}{ }^{-1} 1.73 \mathrm{~m}^{-2}$ in all studies, regardless of initial GFR status.

Five other studies also measured baseline GFR, categorising GFR data retrospectively according to progression or non-progression of AER to at least microalbuminuria over 8 to 13 years (Fig. 3). In all five studies the absolute decline of GFR in progressors was at least twice that in non- progressors. In two of these studies, progression of AER was associated with a final GFR below $100 \mathrm{ml} \mathrm{min}{ }^{-1}$ $1.73 \mathrm{~m}^{-2}[3,62]$. These two small studies were the first to suggest a link between initial hyperfiltration, subsequent increases in AER and lower GFR at the end of follow-up. However, baseline AER was not recorded and the retrospective design of these studies made it difficult to compare them with other studies. In the three subsequent studies [10, $15,63]$, final GFR was in the high normal range in participants with or without progression of AER, despite similar study duration. Whether this indicates that the early decline in GFR observed in hyperfiltering patients represents resolution of hyperfiltration or an early stage of progressive decline in GFR to the subnormal range cannot be answered by the available data.

All of the above data were obtained in observational studies. Recently, one short-term study in streptozotocininduced diabetic rats has shown that hyperfiltration was acutely reduced by $24 \%$ following administration of Cpeptide without altering glycaemic control [64]. Further assessment of the long-term effects of this or similar

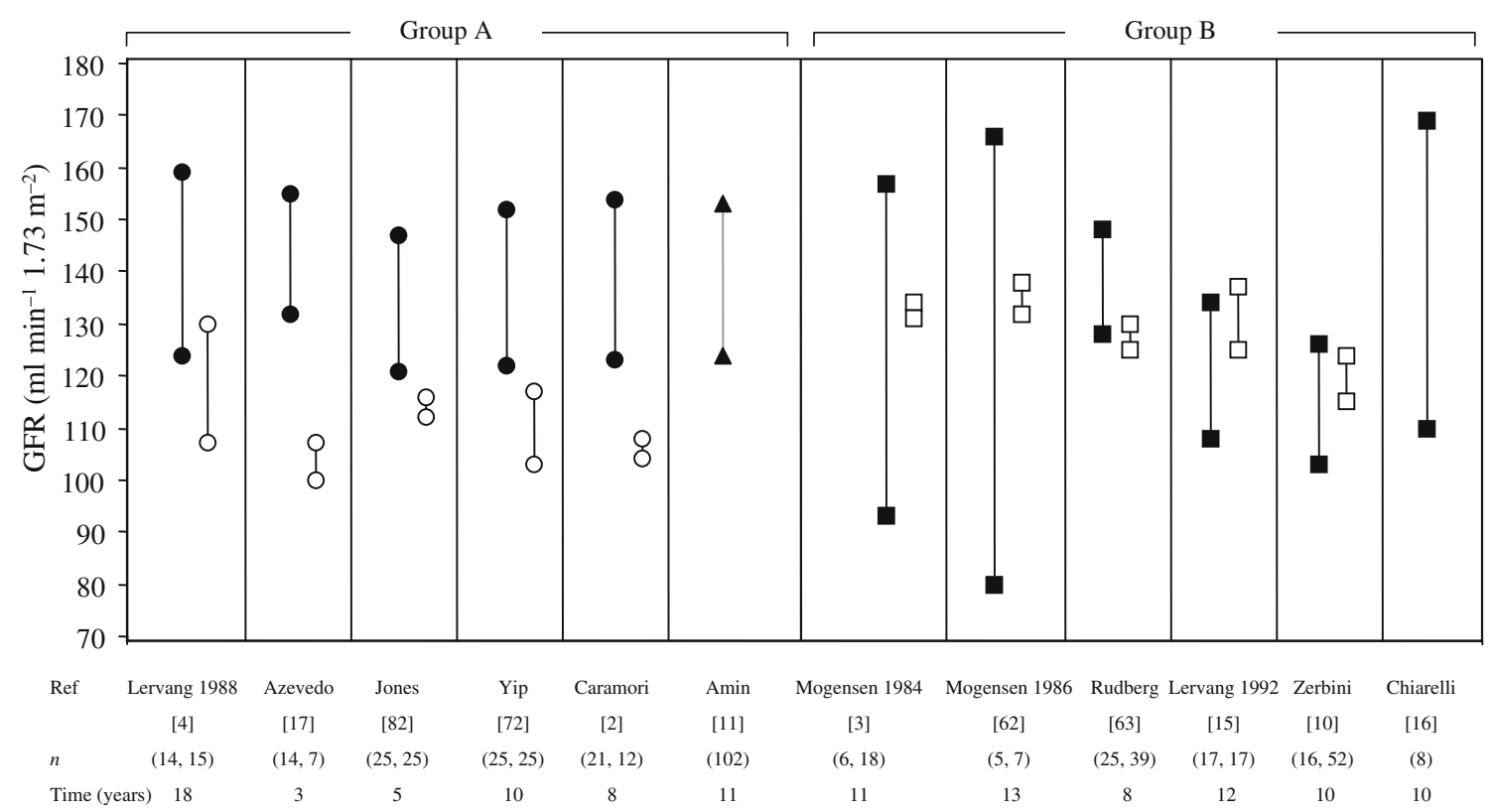

Fig. 3 The two groups show mean baseline and final GFR in subgroups from 12 observational studies (first author [reference no.]) of GFR trajectory over 3 to 18 years in type 1 diabetes. Subgroups are distinguished by colour of symbols (black vs white), study duration was in years as indicated. The initial and the final GFR in the subgroups of each study are represented by the same symbol and joined by a solid line to form a dumb-bell symbol. As baseline GFR exceeded final GFR in all subgroups, the dumb-bells represent the decline in GFR during the study. The six studies in group A show prospective GFR data in subgroups categorised according to the presence of hyperfiltration or normofiltration at baseline. In five of these studies, GFR decline was compared in subgroups with baseline hyperfiltration or normofiltration, with the corresponding number $(n)$

of participants as listed (parentheses). One study (Amin et al. [11]) shows GFR decline in combined hyperfiltration and normofiltration subgroups. Black circles, hyperfiltration; white circles, normofiltration; black triangles, hyperfiltration and normofiltration. The six studies in group B show GFR data in subgroups categorised retrospectively according to progression or non-progression of AER to at least microalbuminuria during the study. In five of these studies, GFR decline was compared in progressors and non-progressors, with the corresponding number $(n)$ of participants as listed (parentheses). One study (Chiarelli et al. [16]) shows GFR decline only in progressors. Black squares, progression of AER; white squares, nonprogression of AER 
interventions, therefore, becomes an important target for future studies.

The studies shown in Fig. 3 generally reflect the course of AER and GFR independently of the effects of renin-angiotensin system (RAS) inhibition. More recently, RAS inhibition has become standard therapy for normotensive patients with type 1 diabetes and microalbuminuria. This has resulted in a decrease or even normalisation of AER in many, but not all patients. However, the subsequent GFR trajectory at this early stage of nephropathy is not predicted by the extent of initial AER lowering by antihypertensive therapy [65]. Initiation of antihypertensive therapy has also been shown to result in reversible decreases in GFR of around $10 \%$ [66], an effect not limited to RAS inhibitors. In normoalbuminuric, normotensive patients with type 1 diabetes, RAS inhibition has not been shown to prevent progression from normo- to microalbuminuria [67]. By contrast, in hypertensive patients with type 2 diabetes, progression from normoto microalbuminuria has been prevented by RAS inhibition using trandolapril, but not by similar blood pressure reduction with verapamil [68].

\section{Relationship of hyperfiltration to progression of albuminuria in type 1 diabetes: clinical studies}

Two recent publications have addressed the relationship between hyperfiltration and progression of albuminuria in type 1 diabetes patients and have arrived at different conclusions (Table 1). The first was a study-level metaanalysis of ten cohort studies of 780 normoalbuminuric patients with a mean follow-up of 11.2 years [7]. The pooled odds of progression were significantly higher in patients with hyperfiltration at baseline. The second was a single-centre study of 426 normoalbuminuric patients attending the Joslin Clinic, with a follow-up of 5, 10 and 15 years [8]. This study found that the risk of progression to microalbuminuria was not increased by hyperfiltration. Adjustment for the duration of hyperfiltration, thereby eliminating regression dilution bias [69], and adjustment for other confounding factors did not alter the results [8].

A comparison of group mean baseline $\mathrm{HbA}_{1 \mathrm{c}}$ levels in the above two studies supports a confounding role for $\mathrm{HbA}_{1 \mathrm{c}}$ since overall $\mathrm{HbA}_{1 \mathrm{c}}$ levels were at least $1 \%$ higher in the meta-analysis than in the Joslin Clinic study (Table 1).
Table 1 Relationship between hyperfiltration and progression to at least microalbuminuria in patients with type 1 diabetes

Unless otherwise indicated, values are expressed as means $\mathrm{HF}$, hyperfiltration; NF, normofiltration

${ }^{\mathrm{a}}$ Ten studies published 1984-2006

${ }^{\mathrm{b}}$ OR $(95 \% \mathrm{CI})$ [7], HR $(95 \% \mathrm{CI})$ [8]

${ }^{\mathrm{c}}$ At 15 years; the hazard ratio was not changed substantially after adjustment for mean $\mathrm{HbA}_{1 \mathrm{c}}$, age at diagnosis, diabetes duration and current cigarette smoking

\begin{tabular}{|c|c|c|}
\hline Variables & Magee et al. [7] & Ficociello et al. [8] \\
\hline Study type & Meta-analysis $^{\mathrm{a}}$ & Single-centre \\
\hline Participants, $n$ (range) & $24-273$ & \\
\hline Total participants $(n)$ & 780 & 426 \\
\hline \multicolumn{3}{|l|}{ Age at diagnosis (years) } \\
\hline Unspecified & 12.3 & \\
\hline NF & & 19 \\
\hline $\mathrm{HF}$ & & 15 \\
\hline \multicolumn{3}{|l|}{ Diabetes duration (years) } \\
\hline Unspecified & 8.1 & \\
\hline NF & & 14 \\
\hline $\mathrm{HF}$ & & 12 \\
\hline Study follow-up (years) & 11.2 & $5,10,15$ \\
\hline \multicolumn{3}{|l|}{ Baseline $\mathrm{HbA}_{1 \mathrm{c}}, \%$ ( $n$ participants) } \\
\hline Progressors [7], NF [8] & $10.5(130)$ & $8.2(315)$ \\
\hline Non-progressors [7], HF [8] & $9.6(650)$ & $8.5(111)$ \\
\hline \multicolumn{3}{|l|}{ Definition of HF $\left(\mathrm{ml} \mathrm{min}{ }^{-1} 1.73 \mathrm{~m}^{-2}\right)$} \\
\hline All (range) & $125-140$ & \\
\hline Men & & $>134$ \\
\hline Women & & $>149$ \\
\hline \multicolumn{3}{|l|}{$\mathrm{HF}$} \\
\hline GFR method & Various & Cystatin C \\
\hline Prevalence at baseline (\%) & 24 & 32 \\
\hline \multicolumn{3}{|c|}{ Patients progressing to at least microalbuminuria } \\
\hline According to NF at baseline (\%) & 12 & 23 \\
\hline According to HF at baseline (\%) & 21 & 19 \\
\hline Risk of progression: $\mathrm{HF}$ vs $\mathrm{NF}^{\mathrm{b}}$ & $2.71(1.20-6.11)$ & $0.8(0.5-14)^{\mathrm{c}}$ \\
\hline
\end{tabular}


It is therefore possible that uncontrolled hyperglycaemia may have contributed to hyperfiltration to a greater degree in earlier studies included in the meta-analysis than in the recent single-centre study [8].

\section{Are divergent results due to differences in definition of progression of albuminuria?}

There are several possible explanations for the divergent results reported in the meta-analysis [7] compared with those found in the Joslin clinic study [8]. Apart from the differences in mean $\mathrm{HbA}_{1 \mathrm{c}}$ levels mentioned above, it is possible that differences in the definition of progression of albuminuria may have influenced the results (Table 2).

Although persistent microalbuminuria has traditionally been classified according to a consensus definition of two out of three consecutive measurements exceeding $20 \mu \mathrm{g} / \mathrm{min}$ [70], more recent studies indicate that this definition may not ensure persistence of microalbuminuria in patients with type 1 diabetes on subsequent follow-up. When using the standard definition, spontaneous regression of microalbuminuria to normoalbuminuria has been reported to occur in $35 \%$ to $64 \%$ of patients [61]. Furthermore, a 6 year cumulative incidence of regression of microalbuminuria (decrease by $50 \%$ ) was reported in $58 \%$ of patients with type 1 diabetes, independently of the use of ACE inhibitors [71].

Four $[3,11,16,61]$ of the ten studies $[2-4,9-11,15,16$, $61,72]$ in the meta-analysis used either a more rigorous definition of persistence of increases of AER or a more advanced stage of progression of AER than the standard definition of microalbuminuria (Table 2). Three of these four studies $[3,11,16]$ reported a significant odds ratio for the association between baseline hyperfiltration and subsequent progression to at least microalbuminuria [7]. By contrast none of the remaining six studies $[2,4,9,10,15$, 72] in the meta-analysis that used the conventional definition of microalbuminuria demonstrated a significant odds ratio. It is, therefore, possible that differences in the definition of microalbuminuria contributed to the significant relationship between hyperfiltration and progression of AER in the meta-analysis. In the Joslin Clinic study, progression to microalbuminuria was defined as two consecutive measurements $>30 \mu \mathrm{g} / \mathrm{min}$ [8]. This would not have excluded transient microalbuminuria and may explain the lack of association between hyperfiltration and progression of AER in that study.

\section{Relationship of hyperfiltration to subsequent decline of GFR: clinical studies}

Assessment of the relationship between hyperfiltration and subsequent GFR decline is subject to several methodological difficulties. These include distinction between resolution of hyperfiltration and onset of a progressive decline in GFR to subnormal levels. Distinction between these two variants of GFR trajectory has so far not been achieved, perhaps because study duration has been too short. An additional methodological problem relates to the difficulty in using current methods to estimate GFR at higher levels of GFR. In a recent comparison of rates of decline of GFR in type 1 diabetes at our centre, serial estimates of GFR decline by creatinine-based methods in patients with an initial isotopically measured GFR of $106 \pm 2.6 \mathrm{ml} \mathrm{min}$ $1.73 \mathrm{~m}^{-2}$ underestimated the GFR gradient measured isotopically by over $50 \%$ during a follow-up of 10 years [73]. In contrast, we and others have shown that cystatin Cbased methods for estimating GFR accurately reflect reference GFR measurements in the normal to high range [73-76].

Matching for known duration of disease may help to partly resolve the difficulty of interpreting GFR trajectories in type 1 diabetes. However, it may not exclude the

Table 2 Criteria for progression to at least microalbuminuria in individual studies in Magee meta-analysis [7]

\begin{tabular}{|c|c|c|}
\hline Study (first author [reference no.]) & Definition of progression of AER $(\mu \mathrm{g} / \mathrm{min})$ & $\begin{array}{l}\text { Relationship of } \mathrm{HF}^{\mathrm{a}} \text { to } \\
\text { progression of } \mathrm{AER}^{\mathrm{b}}\end{array}$ \\
\hline $\begin{array}{l}\text { Lervang [4], Lervang [15], Yip [72], Caramori [2], } \\
\text { Dahlquist [9], Zerbini [10] }\end{array}$ & $>20$ in 2 out of 3 consecutive collections & $0 / 6$ \\
\hline Chiarelli [16] & $>30$ in 5 consecutive collections & $1 / 1$ \\
\hline Amin [11] & $\begin{array}{l}>20 \text { in } 2 \text { out of } 3 \text { consecutive collections for at least } \\
2 \text { consecutive years }\end{array}$ & $1 / 1$ \\
\hline Steinke [61] & $\begin{array}{l}>20 \text { in } 2 \text { out of } 3 \text { consecutive collections including } \\
\text { end of study }\end{array}$ & $0 / 1$ \\
\hline Mogensen $[3]^{\mathrm{c}}$ & $>150$ at end of study (macroalbuminuria) & $1 / 1$ \\
\hline
\end{tabular}


possibility of hyperfiltration preceding the diagnosis of type 2 diabetes, since the onset of type 2 diabetes may occur up to 7 years prior to diagnosis [77].

Several additional aspects need to be considered when interpreting rates of change of GFR (Fig. 4). First, decreases in GFR shortly after initiation of insulin therapy may indicate a beneficial correction of hyperfiltration. Second, GFR may decline more rapidly in initially hyperfiltering than in normofiltering patients. This would be reflected by non-parallel GFR gradients with steeper rates of decline associated with higher baseline GFR levels. Third, the proportion of patients with progressive declines in GFR may be greater in hyperfiltering than in normofiltering patients even though the individual rates of decline are similar. If this were the case, differences in the proportion of patients with progression of nephropathy would not be revealed in case-control studies.

A recent preliminary report describes a much longer follow-up of GFR to subnormal levels. This report from the Pittsburgh Epidemiology of Diabetes Complications Study suggests that renal hyperfiltration may increase the risk of subsequent renal impairment [78]. During 18 years of follow-up of a cohort of 423 individuals with childhood onset 1 diabetes and mean diabetes duration of 18 years at entry, 9.3\% developed an estimated GFR $<60 \mathrm{ml} \mathrm{m^{-1 }}$ $1.73 \mathrm{~m}^{-2}$ using the Cockcroft-Gault formula. Multivariate analysis adjusted for baseline GFR showed that hyperfiltration was a strong risk factor for renal impairment, but not for overt nephropathy (AER $>200 \mu \mathrm{g} / \mathrm{min}$ ). However, the results were not confirmed when GFR was estimated by the Modification of Diet in Renal Disease formula [79]. Further long-term studies of GFR trajectory are therefore needed in order to define the presence or absence of a pathogenetic role for hyperfiltration in diabetic renal disease. A further complicating factor in long-term studies of type 1 diabetes is that individuals with an estimated GFR $>120 \mathrm{ml} \mathrm{min}{ }^{-1} 1.73^{-2}$ display increased mortality independent of the presence or severity of albuminuria [80].

\section{Conclusions}

Marked differences in the prevalence of hyperfiltration have been reported over the years and there have been widely contrasting conclusions on the relationship between hyperfiltration and onset of microalbuminuria and/or subsequent decline in GFR to subnormal levels in patients with type 1 diabetes. Interpretation and definition of hyperfiltration in type 2 diabetes has been difficult, in particular because of the effect of age on GFR levels. While differences in methods of GFR measurement and evaluation undoubtedly play a part, it is likely that the calendar effect is a major contributor to the diverging results. Over the last 20 years, the incidence of nephropathy in type 1 diabetes has become substantially lower than reported historically. For instance, in the DCCT/EDIC study, the 30 year cumulative incidence of nephropathy (AER $\geq 300 \mu \mathrm{g} / 24 \mathrm{~h}$ or serum creatinine $\geq 177 \mu \mathrm{mol} / \mathrm{l}$ ) was only $9 \%$ and $25 \%$ in the original intensive and conventional glycaemic control groups, respectively [81]. In addition, conventional therapy for diabetes has now extended to control of blood pressure, dyslipidaemia and smoking. The resulting changes in these variables may account for alterations not only in the prevalence of hyperfiltration but also in the evolution of long-term changes in AER and GFR.

In summary, at present the available data in support of a pathogenetic role for hyperfiltration in diabetic nephropathy are too weak to allow reliable conclusions. The available studies suffer from one or more of the following defects: they are too small, far too short and have failed to control for confounders. In addition, the putative link between hyperfiltration and onset of nephropathy has focussed entirely on albuminuria and the definition of progression of albuminuria has been variable. By contrast, no study has shown prospectively that hyperfiltration leads to subnormal GFR independently of other variables. It is, therefore, possible that definitive assessment of a pathogenetic role for hyperfiltration in diabetic nephropathy may require the development of interventions that bypass glycaemic control and target GFR specifically.
Fig. 4 Potential relationship of hyperfiltration to subsequent GFR decline. Graphs show that GFR decline (a) occurs more rapidly, (b) is more prevalent and (c) happens earlier in hyperfiltration than in normofiltration. Black lines, initial hyperfiltration progressing to subnormal GFR; grey lines, normofiltration progressing to subnormal GFR; dotted line, resolution of hyperfiltration without decline to subnormal GFR

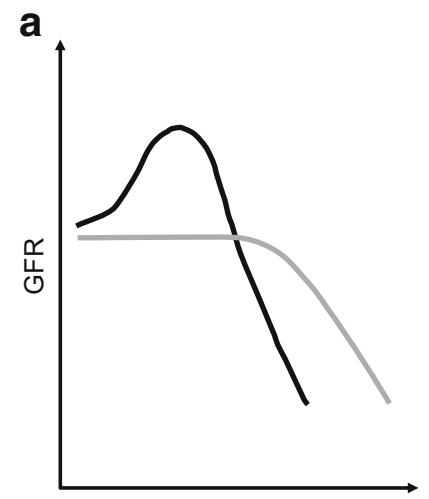

Duration of diabetes

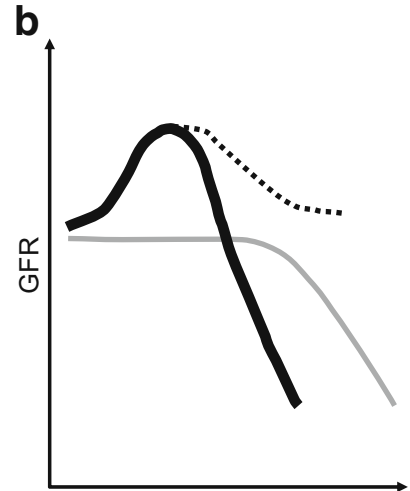

Duration of diabetes

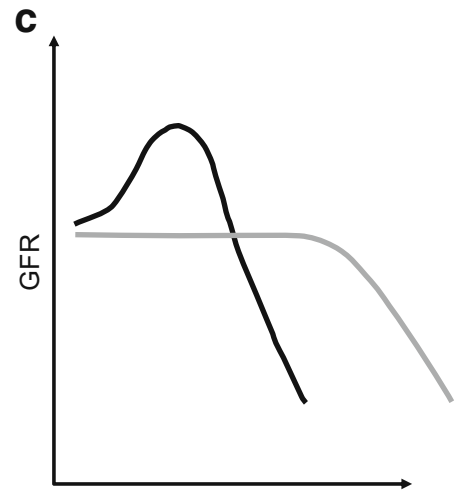

Duration of diabetes 
Acknowledgements This work was presented in part at the I.S.N. Nexus Symposium on 'Diabetes and the Kidney', in Dublin, June 2008. We wish to thank G. Viberti and A. Krolewski for helpful discussions in compiling this review.

Duality of interest The authors declare that there is no duality of interest associated with this manuscript.

\section{References}

1. Wiseman MJ, Saunders AJ, Keen H, Viberti G (1985) Effect of blood glucose control on increased glomerular filtration rate and kidney size in insulin-dependent diabetes. N Engl J Med 312:617621

2. Caramori ML, Gross JL, Pecis M, de Azevedo MJ (1999) Glomerular filtration rate, urinary albumin excretion rate, and blood pressure changes in normoalbuminuric normotensive type 1 diabetic patients: an 8-year follow-up study. Diabetes Care 22:1512-1516

3. Mogensen CE, Christensen CK (1984) Predicting diabetic nephropathy in insulin-dependent patients. $\mathrm{N}$ Engl J Med 311:89-93

4. Lervang HH, Jensen S, Brochner-Mortensen J, Ditzel J (1988) Early glomerular hyperfiltration and the development of late nephropathy in type 1 (insulin-dependent) diabetes mellitus. Diabetologia 31:723-729

5. Brenner BM (1983) Hemodynamically mediated glomerular injury and the progressive nature of kidney disease. Kidney Int 23:647-655

6. Hostetter TH, Olson JL, Rennke HG, Venkatachalam MA, Brenner BM (1981) Hyperfiltration in remnant nephrons: a potentially adverse response to renal ablation. Am J Physiol 241:F85-F93

7. Magee GM, Bilous RW, Cardwell CR, Hunter SJ, Kee F, Fogarty DG (2009) Is hyperfiltration associated with the future risk of developing diabetic nephropathy? A meta-analysis. Diabetologia 52:691-697

8. Ficociello LH, Perkins BA, Roshan B et al (2009) Renal hyperfiltration and the development of microalbuminuria in type 1 diabetes. Diabetes Care 32:889-893

9. Dahlquist G, Stattin EL, Rudberg S (2001) Urinary albumin excretion rate and glomerular filtration rate in the prediction of diabetic nephropathy; a long-term follow-up study of childhood onset type-1 diabetic patients. Nephrol Dial Transplant 16:13821386

10. Zerbini G, Bonfanti R, Meschi F et al (2006) Persistent renal hypertrophy and faster decline of glomerular filtration rate precede the development of microalbuminuria in type 1 diabetes. Diabetes 55:2620-2625

11. Amin R, Turner C, van Aken S et al (2005) The relationship between microalbuminuria and glomerular filtration rate in young type 1 diabetic subjects: The Oxford Regional Prospective Study. Kidney Int 68:1740-1749

12. Chaiken RL, Eckert-Norton M, Bard M et al (1998) Hyperfiltration in African-American patients with type 2 diabetes. Cross-sectional and longitudinal data. Diabetes Care 21:2129-2134

13. Brochner-Mortensen J (1972) A simple method for the determination of glomerular filtration rate. Scand $\mathrm{J}$ Clin Lab Invest 30:271-274

14. Houlihan C, Jenkins M, Osicka T, Scott A, Parkin D, Jerums G (1999) A comparison of the plasma disappearance of iohexol and ${ }^{99 m}$ Tc-DTPA for the measurement of glomerular filtration rate (GFR) in diabetes. Aust N Z J Med 29:693-700
15. Lervang HH, Jensen S, Brochner-Mortensen J, Ditzel J (1992) Does increased glomerular filtration rate or disturbed tubular function early in the course of childhood type 1 diabetes predict the development of nephropathy? Diabet Med 9:635-640

16. Chiarelli F, Verrotti A, Morgese G (1995) Glomerular hyperfiltration increases the risk of developing microalbuminuria in diabetic children. Pediatr Nephrol 9:154-158

17. Azevedo MJ, Gross JL (1991) Follow-up of glomerular hyperfiltration in normoalbuminuric type 1 (insulin-dependent) diabetic patients. Diabetologia 34:611

18. Mogensen CE, Andersen MJ (1975) Increased kidney size and glomerular filtration rate in untreated juvenile diabetes: normalization by insulin-treatment. Diabetologia 11:221-224

19. Wiseman MJ, Viberti GC, Keen H (1984) Threshold effect of plasma glucose in the glomerular hyperfiltration of diabetes. Nephron 38:257-260

20. Wiseman MJ, Mangili R, Alberetto M, Keen H, Viberti G (1987) Glomerular response mechanisms to glycemic changes in insulindependent diabetics. Kidney Int 31:1012-1018

21. Schmitz A (1993) Renal function changes in middle-aged and elderly Caucasian type 2 (non-insulin-dependent) diabetic patients - a review. Diabetologia 36:985-992

22. Damsgaard EM, Mogensen CE (1986) Microalbuminuria in elderly hyperglycaemic patients and controls. Diabet Med 3:430-435

23. Gragnoli G, Signorini AM, Tanganelli I et al (1993) Prevalence of glomerular hyperfiltration and nephromegaly in normo- and microalbuminuric type 2 diabetic patients. Nephron 65:206-211

24. Vora JP, Dolben J, Dean JD et al (1992) Renal hemodynamics in newly presenting non-insulin dependent diabetes mellitus. Kidney Int 41:829-835

25. Silveiro SP, Friedman R, de Azevedo MJ, Canani LH, Gross JL (1996) Five-year prospective study of glomerular filtration rate and albumin excretion rate in normofiltering and hyperfiltering normoalbuminuric NIDDM patients. Diabetes Care 19:171-174

26. Vedel P, Obel J, Nielsen FS et al (1996) Glomerular hyperfiltration in microalbuminuric NIDDM patients. Diabetologia 39:1584-1589

27. Rius F, Pizaro E, Salinas I, Lucas A, Sanmarti A, Romero R (1995) Age as a determinant of glomerular filtration rate in noninsulin-dependent diabetes mellitus. Nephrol Dial Transplant 10:1644-1647

28. Premaratne E, MacIsaac RJ, Tsalamandris C, Panagiotopoulos S, Smith T, Jerums G (2005) Renal hyperfiltration in type 2 diabetes: effect of age-related decline in glomerular filtration rate. Diabetologia 48:2486-2493

29. Myers BD, Nelson RG, Williams GW et al (1991) Glomerular function in Pima Indians with noninsulin-dependent diabetes mellitus of recent onset. J Clin Invest 88:524-530

30. Nelson RG, Bennett PH, Beck GJ et al (1996) Development and progression of renal disease in Pima Indians with non-insulindependent diabetes mellitus. Diabetic Renal Disease Study Group. N Engl J Med 335:1636-1642

31. Nielsen S, Schmitz A, Rehling M, Mogensen CE (1993) Systolic blood pressure relates to the rate of decline of glomerular filtration rate in type II diabetes. Diabetes Care 16:1427-1432

32. Chagnac A, Herman M, Zingerman B et al (2008) Obesity-induced glomerular hyperfiltration: its involvement in the pathogenesis of tubular sodium reabsorption. Nephrol Dial Transplant 23:3946-3952

33. Tomaszewski M, Charchar FJ, Maric C et al (2007) Glomerular hyperfiltration: a new marker of metabolic risk. Kidney Int 71:816-821

34. Monami M, Pala L, Bardini G et al (2009) Glomerular hyperfiltration and metabolic syndrome: results from the FIrenze-BAgno A Ripoli (FIBAR) Study. Acta Diabetol 46:191-196 
35. Chagnac A, Weinstein T, Korzets A, Ramadan E, Hirsch J, Gafter U (2000) Glomerular hemodynamics in severe obesity. Am J Physiol Renal Physiol 278:F817-F822

36. Chagnac A, Weinstein T, Herman M, Hirsh J, Gafter U, Ori Y (2003) The effects of weight loss on renal function in patients with severe obesity. J Am Soc Nephrol 14:1480-1486

37. Schmieder RE, Messerli FH, Garavaglia G, Nunez B (1990) Glomerular hyperfiltration indicates early target organ damage in essential hypertension. JAMA 264:2775-2780

38. Palatini P, Mormino P, Dorigatti F et al (2006) Glomerular hyperfiltration predicts the development of microalbuminuria in stage 1 hypertension: the HARVEST. Kidney Int 70:578-584

39. Verhave JC, Hillege HL, Burgerhof JG, Gansevoort RT, de Zeeuw D, de Jong PE (2005) The association between atherosclerotic risk factors and renal function in the general population. Kidney Int 67:1967-1973

40. Pinto-Sietsma SJ, Janssen WM, Hillege HL, Navis G, De Zeeuw D, De Jong PE (2000) Urinary albumin excretion is associated with renal functional abnormalities in a nondiabetic population. J Am Soc Nephrol 11:1882-1888

41. Zatz R, Meyer TW, Rennke HG, Brenner BM (1985) Predominance of hemodynamic rather than metabolic factors in the pathogenesis of diabetic glomerulopathy. Proc Natl Acad Sci U S A 82:5963-5967

42. Brenner BM, Meyer TW, Hostetter TH (1982) Dietary protein intake and the progressive nature of kidney disease: the role of hemodynamically mediated glomerular injury in the pathogenesis of progressive glomerular sclerosis in aging, renal ablation, and intrinsic renal disease. N Engl J Med 307:652-659

43. Vallon V, Richter K, Blantz RC, Thomson S, Osswald H (1999) Glomerular hyperfiltration in experimental diabetes mellitus: potential role of tubular reabsorption. J Am Soc Nephrol 10:2569-2576

44. Thomson SC, Deng A, Bao D, Satriano J, Blantz RC, Vallon V (2001) Ornithine decarboxylase, kidney size, and the tubular hypothesis of glomerular hyperfiltration in experimental diabetes. J Clin Invest 107:217-224

45. Vervoort G, Veldman B, Berden JH, Smits P, Wetzels JF (2005) Glomerular hyperfiltration in type 1 diabetes mellitus results from primary changes in proximal tubular sodium handling without changes in volume expansion. Eur J Clin Invest 35:330-336

46. Sallstrom J, Carlsson PO, Fredholm BB, Larsson E, Persson AE, Palm F (2007) Diabetes-induced hyperfiltration in adenosine A (1)-receptor deficient mice lacking the tubuloglomerular feedback mechanism. Acta Physiol (Oxf) 190:253-259

47. Mogensen CE, Andersen MJ (1973) Increased kidney size and glomerular filtration rate in early juvenile diabetes. Diabetes 22:706-712

48. Hostetter TH (2001) Hypertrophy and hyperfunction of the diabetic kidney. J Clin Invest 107:161-162

49. Bak M, Thomsen K, Christiansen T, Flyvbjerg A (2000) Renal enlargement precedes renal hyperfiltration in early experimental diabetes in rats. J Am Soc Nephrol 11:1287-1292

50. Lawson ML, Sochett EB, Chait PG, Balfe JW, Daneman D (1996) Effect of puberty on markers of glomerular hypertrophy and hypertension in IDDM. Diabetes 45:51-55

51. Walker JD, Bending JJ, Dodds RA et al (1989) Restriction of dietary protein and progression of renal failure in diabetic nephropathy. Lancet 2:1411-1415

52. Zeller K, Whittaker E, Sullivan L, Raskin P, Jacobson HR (1991) Effect of restricting dietary protein on the progression of renal failure in patients with insulin-dependent diabetes mellitus. N Eng1 J Med 324:78-84

53. Zatz R, Dunn BR, Meyer TW, Anderson S, Rennke HG, Brenner BM (1986) Prevention of diabetic glomerulopathy by pharmacological amelioration of glomerular capillary hypertension. J Clin Invest 77:1925-1930

54. Nenov VD, Taal MW, Sakharova OV, Brenner BM (2000) Multihit nature of chronic renal disease. Curr Opin Nephrol Hypertens 9:85-97

55. Taal MW, Brenner BM (2000) Renoprotective benefits of RAS inhibition: from ACEI to angiotensin II antagonists. Kidney Int 57:1803-1817

56. Rossing P, Tarnow L, Nielsen FS, Hansen BV, Brenner BM, Parving HH (1995) Low birth weight. A risk factor for development of diabetic nephropathy? Diabetes 44:1405-1407

57. Chang S, Caramori ML, Moriya R, Mauer M (2008) Having one kidney does not accelerate the rate of development of diabetic nephropathy lesions in type 1 diabetic patients. Diabetes 57:17071711

58. Rudberg S, Osterby R, Dahlquist G, Nyberg G, Persson B (1997) Predictors of renal morphological changes in the early stage of microalbuminuria in adolescents with IDDM. Diabetes Care 20:265-271

59. Berg UB, Torbjornsdotter TB, Jaremko G, Thalme B (1998) Kidney morphological changes in relation to long-term renal function and metabolic control in adolescents with IDDM. Diabetologia 41:1047-1056

60. Drummond K, Mauer M (2002) The early natural history of nephropathy in type 1 diabetes: II. Early renal structural changes in type 1 diabetes. Diabetes 51:1580-1587

61. Steinke JM, Sinaiko AR, Kramer MS, Suissa S, Chavers BM, Mauer M (2005) The early natural history of nephropathy in type 1 diabetes: III. Predictors of 5-year urinary albumin excretion rate patterns in initially normoalbuminuric patients. Diabetes 54:2164-2171

62. Mogensen CE (1986) Early glomerular hyperfiltration in insulindependent diabetics and late nephropathy. Scand J Clin Lab Invest 46:201-206

63. Rudberg S, Persson B, Dahlquist G (1992) Increased glomerular filtration rate as a predictor of diabetic nephropathy-an 8-year prospective study. Kidney Int 41:822-828

64. Nordquist L, Brown R, Fasching A, Persson P, Palm F (2009) Proinsulin C-peptide reduces diabetes-induced glomerular hyperfiltration via efferent arteriole dilation and inhibition of tubular sodium reabsorption. Am J Physiol Renal Physiol 297:F1265-F1272

65. Bakris GL, Ritz E (2009) The message for World Kidney Day 2009: hypertension and kidney disease: a marriage that should be prevented. Am J Nephrol 30:95-98

66. Hansen HP, Rossing P, Tarnow L, Nielsen FS, Jensen BR, Parving HH (1995) Increased glomerular filtration rate after withdrawal of long-term antihypertensive treatment in diabetic nephropathy. Kidney Int 47:1726-1731

67. Mauer M, Zinman B, Gardiner R et al (2009) Renal and retinal effects of enalapril and losartan in type 1 diabetes. N Engl J Med $361: 40-51$

68. Ruggenenti P, Fassi A, Ilieva AP et al (2004) Preventing microalbuminuria in type 2 diabetes. N Engl J Med 351:1941-1951

69. MacMahon S, Peto R, Cutler J et al (1990) Blood pressure, stroke, and coronary heart disease. Part 1, Prolonged differences in blood pressure: prospective observational studies corrected for the regression dilution bias. Lancet 335:765-774

70. Mogensen CE, Chachati A, Christensen CK et al (1985) Microalbuminuria: an early marker of renal involvement in diabetes. Uremia Invest 9:85-95

71. Perkins BA, Ficociello LH, Silva KH, Finkelstein DM, Warram JH, Krolewski AS (2003) Regression of microalbuminuria in type 1 diabetes. N Engl J Med 348:2285-2293

72. Yip JW, Jones SL, Wiseman MJ, Hill C, Viberti G (1996) Glomerular hyperfiltration in the prediction of nephropathy in IDDM: a 10-year follow-up study. Diabetes 45:1729-1733

73. Premaratne E, MacIsaac R, Finch S, Panagiotopoulos S, Ekinci E, Jerums G (2008) Serial measurements of cystatin C are more 
accurate than creatinine-based methods indetecting declining renal function in type 1 diabetes. Diabetes Care 31:971-973

74. MacIsaac RJ, Tsalamandris C, Thomas MC et al (2006) Estimating glomerular filtration rate in diabetes: a comparison of cystatin-C- and creatinine-based methods. Diabetologia 49:1686-1689

75. MacIsaac RJ, Tsalamandris C, Thomas MC et al (2007) The accuracy of cystatin $\mathrm{C}$ and commonly used creatinine-based methods for detecting moderate and mild chronic kidney disease in diabetes. Diabet Med 24:443-448

76. Perkins BA, Nelson RG, Ostrander BE et al (2005) Detection of renal function decline in patients with diabetes and normal or elevated GFR by serial measurements of serum cystatin $\mathrm{C}$ concentration: results of a 4-year follow-up study. J Am Soc Nephrol 16:1404-1412

77. Harris MI, Klein R, Welborn TA, Knuiman MW (1992) Onset of NIDDM occurs at least 4-7 yr before clinical diagnosis. Diabetes Care 15:815-819

78. Costacou T, Orchard TJ (2009) Renal hyperfiltration in relation to low renal function and incidence of overt nephropathy among individuals with type 1 diabetes. Diabetologia 52(Supp. 1): S414

79. Levey AS, Bosch JP, Lewis JB, Greene T, Rogers N, Roth D (1999) A more accurate method to estimate glomerular filtration rate from serum creatinine: a new prediction equation. Modification of Diet in Renal Disease Study Group. Ann Intern Med 130:461-470

80. Groop P-H, Thomas MC, Moran JL et al (2009) The presence and severity of chronic kidney disease predicts all-cause mortality in type 1 diabetes. Diabetes 58:1651-1658

81. DCCT/EDIC Research Group, Nathan DM, Zinman B et al (2009) Modern-day clinical course of type 1 diabetes mellitus after 30 years' duration: the diabetes control and complications trial/ epidemiology of diabetes interventions and complications and Pittsburgh epidemiology of diabetes complications experience (1983-2005). Arch Intern Med 169:1307-1316

82. Jones SL, Wiseman MJ, Viberti GC (1991) Glomerular hyperfiltration as a risk factor for diabetic nephropathy: five-year report of a prospective study. Diabetologia 34:59-60 